\title{
Utilization of a Novel Chitosan/Clay/Biochar Nanobiocomposite for Immobilization of Heavy Metals in Acid Soil Environment
}

\author{
Hoda Arabyarmohammadi ${ }^{1}$ Ahmad Khodadadi Darban ${ }^{1} \cdot$ Mahmoud Abdollahy $^{1}$. \\ Raymond Yong $^{2}$ - Bita Ayati ${ }^{3}$ Abbas Zirakjou ${ }^{4}$ Sjoerd E. A. T. M. van der Zee ${ }^{5,6}$
}

Published online: 15 September 2017

(C) The Author(s) 2017. This article is an open access publication

\begin{abstract}
An organic-inorganic composite of chitosan, nanoclay, and biochar (named as MTCB) was chosen to develop a bionanocomposite to simultaneously immobilize $\mathrm{Cu}, \mathrm{Pb}$, and $\mathrm{Zn}$ metal ions within the contaminated soil and water environments. The composite material was structurally and chemically characterized with the XRD, TEM, SEM, BET, and FT-IR techniques. XRD and TEM results revealed that a mixed exfoliated/intercalated morphology was formed upon addition of small amounts of nanoclay (5\% by weight). Batch adsorption experiments showed that the adsorption capacity of MTCB for $\mathrm{Cu}^{2+}, \mathrm{Pb}^{2+}$, and $\mathrm{Zn}^{2+}$ were much higher than that of the pristine biochar sample (121.5, 336, and $134.6 \mathrm{mg} \mathrm{g}^{-1}$ for $\mathrm{Cu}^{2+}, \mathrm{Pb}^{2+}$, and $\mathrm{Zn}^{2+}$, respectively). The adsorption isotherm for $\mathrm{Cu}^{2+}$ and $\mathrm{Zn}^{2+}$ fitted satisfactorily to a Freundlich model while the isotherm of $\mathrm{Pb}^{2+}$ was best represented by a Temkin model. That the adsorption capacity increased with increasing temperature is indicative of the endothermic nature of the adsorption process. According to the FTIR analysis, the main mechanism involved in
\end{abstract}

Ahmad Khodadadi Darban

akdarban@modares.ac.ir

1 Mineral Processing Group, Mining Engineering Department, Tarbiat Modares University, Tehran, Iran

2 William Scott Professor Emeritus of Civil Engineering, McGill University, Montreal, QC, Canada

3 Civil and Environmental Engineering Department, Tarbiat Modares University, Tehran, Iran

4 Nanomaterials Group, Materials Engineering Department, Tarbiat Modares University, Tehran, Iran

5 Soil Physics and Land Management Group, Wageningen University, Wageningen, The Netherlands

6 School of Chemistry, Monash University, Melbourne, VIC, Australia immobilization of metals is binding with $-\mathrm{NH}_{2}$ groups. Results from this study indicated that modification of biochar by chitosan/clay nanocomposite enhances its potential capacity for immobilization of heavy metals, rendering the bionanocomposite into an efficient heavy metal sorbent in mine-impacted acidic waters and soils.

Keywords Heavy metals - Nanobiocomposite - Biochar . Soil · Immobilization · SPLP

\section{Introduction}

Mineral and metallurgical processes are major sources of soil pollution worldwide. These industrial activities use large volumes of water and produce huge amounts of different types of wastes. Mine tailings, for instance, form an important source of heavy metals with high concentrations of $\mathrm{Cu}, \mathrm{Pb}, \mathrm{Zn}, \mathrm{Cd}, \mathrm{Cr}$ and $\mathrm{As}$ [1]. Often, these tailings are rich in sulfide minerals which are readily oxidized when exposed to water and air to produce sulfuric acid. Under such (very) acid conditions, heavy metals become mobile and are easily leached out of the tailing deposits. Therefore, both tailings and their leaching water are known to lead to soil contamination [2] and necessitate measures to mitigate or prevent heavy metals contamination. For this purpose, various physicochemical mechanisms are known to render metals immobile and biologically unavailable [3]. There are several techniques have been developed for remediating mine tailings such as landfilling, thermal treatment, electro reclamation and soil capping. However, all are costly and environmentally unfavorable since at the end, they end in toxic solid/liquid residues which will require an engineered safe disposal, as well [4]. 
It has been shown that biochars are efficient soil amendments to improve soil quality and they are now being commercialized in many countries. The main interesting property of this carbonic material is its high stability and resistance against degradation in soil systems [5]. Because of this feature, biochar maintains the nutrient and water retention capacities in soil, which is of agricultural importance. Additionally, contaminants as toxins, and organic pollutants such as PAHs are immobilized for large time periods [5]. Also regarding the immobilization of heavy metals in soil, use of biochar has been a prominent subject of research $[1,6]$.

Acid copper mine tailings are commonly found in the Sarcheshmeh Copper Complex, where soil is contaminated with several metals such as $\mathrm{Cu}, \mathrm{Zn}$, and $\mathrm{Pb}$. Although biochars have been proposed as a candidate sorbent for these metals, the sorption capacities of most biochars for many heavy metals are smaller than that of some commercial adsorbents [7]. Accordingly, the aim of the present research was to enhance the sorption capacity of biochar through designing a novel biochar-based composite.

Chitosan, one of the most widely used and naturally abundant biopolymers, contains acetamido and amino groups [8]. The presence of these functional groups gives chitosan a cationic polyelectrolyte character and enables it to chelate metal ions $[9,10]$. Since it is a hydrophilic biopolymer, it is potentially biocompatible, environmentally friendly, and suitable to be used in sustainable materials (e.g. adsorbents, coating materials, membranes) $[8$, 9]. Nanoclays including modified and unmodified montmorillonite clays (commercially referred to as the Cloisite series) are widely used as nanofillers or additive materials to improve various physical properties of polymers, such as reinforcement. Montmorillonite clay (MT) is a phyllosilicate formed of Al-O octahedral platelets sandwiched between two $\mathrm{Si}-\mathrm{O}$ tetrahedral sheets. The remarkably large adsorption capacity of this material for metals is mainly due to the specific layered structure and existence of exchangeable hydrated cations [11]. Chitosan based nanocomposites containing MT have been used for dye removal [9, 12-15] and sorption of heavy metals [16-19] from effluents. However, their effect on contaminated soils has not yet been evaluated. Therefore, a second aim of this investigation is to assess the performance of this nanocomposite structure within the soil environment, it is employed onto a sustainable charred matrix material to form a bionanocomposite. The behavior of chitosan/clay modified biochar in immobilization of heavy metals has been investigated afterwards.

\section{Materials and Methods}

\section{Chemicals}

All chemical reagents were of the highest purity that is commercially available. Lead (II) nitrate, copper (II) nitrate, zinc (II) nitrate, sodium chloride, potassium nitrate, acetic acid, nitric acid, sulfuric acid, and sodium hydroxide were purchased from Merck (Merck Millipore, Germany). Chitosan was from Sigma-Aldrich. The source clay, sodium MT (Cloisite $\mathrm{Na}^{+}$), was purchased from Southern Clay Products, Gonzales, TX. The cation exchange capacity (CEC) of Cloisite $\mathrm{Na}^{+}$is $92.6 \times 10^{-5} \mathrm{~mol}_{\mathrm{c}} \mathrm{g}^{-1}$ as reported by suppliers $\left(\mathrm{mol}_{\mathrm{c}}\right.$ stands for mol-charge, formerly called equivalent). Distilled, deionized water (DDW) was used for all procedures.

\section{Soil Sample}

The simulated soil was prepared by mixing $50 \%$ sand, $35 \%$ silt, and $15 \%$ kaolinite according to the mean texture of the polluted soils in vicinity of Sarcheshmeh Copper Mine Complex, Kerman, Iran. The contaminated area is about $400 \mathrm{~km}^{2}$ of the area and mainly involves the top 15 centimeters of soil. The main contamination concerns the metals $\mathrm{Cu}, \mathrm{Pb}$, and $\mathrm{Zn}$. The soil is classified as silty sand (SM) according to ASTM D422 and the Unified Soil Classification System (USCS).

\section{Preparation of Chitosan/Clay/Biochar Nanobiocomposites}

Residual bark chips were collected from Mazandaran Wood and Paper plant site to be used as feedstock and were air-dried overnight. The bark sample was pyrolysed at $600{ }^{\circ} \mathrm{C}$ at $10{ }^{\circ} \mathrm{C} \mathrm{min}{ }^{-1}$ and $2 \mathrm{~h}$ residence time under $3 \mathrm{~L} \mathrm{~min}{ }^{-1}$ nitrogen flow in a chamber furnace (Nabertherm, Germany). The pyrolysis conditions were chosen according to the thermal analysis over the biomass which was performed in advance. The resulting chars were allowed to cool to room temperature, rinsed several times with DDW, dried at $80{ }^{\circ} \mathrm{C}$ in oven, and sieved to $<2 \mathrm{~mm}$. A chitosan aqueous solution was prepared by dissolving $5 \mathrm{~g}$ of chitosan powder in $250 \mathrm{ml}$ acetic acid solution (2\% v/v). A nanoclay suspension with 5\% clay content was prepared by dispersing appropriate amounts of clay in $10 \mathrm{ml}$ of $2 \%$ acetic acid and stirring for $24 \mathrm{~h}$. Afterwards, the chitosan solution was gradually added to the pretreated clay suspension. The final mixture was vigorously stirred for another $24 \mathrm{~h}$ at $60{ }^{\circ} \mathrm{C}$. Finally, $5 \mathrm{~g}$ of biochar was added to the mixture and stirred for $30 \mathrm{~min}$ to provide a homogeneous suspension. The biochar/chitosan/clay suspension was then added drop wise into a $1000 \mathrm{ml} \mathrm{NaOH} \mathrm{(1.2 \% )} \mathrm{solution} \mathrm{and}$ 
kept in the solution for $12 \mathrm{~h}$. Afterwards, the composite material (MTCB) was filtered, washed several times with DDW, and oven dried at $70{ }^{\circ} \mathrm{C}$.

\section{Characterization}

Prior to pyrolysis, to find the proper temperature for charring the biomass, a thermogravimetric analysis (TGA) was performed under nitrogen flow from room temperature to $700{ }^{\circ} \mathrm{C}$ at a rate of $10{ }^{\circ} \mathrm{C} \mathrm{min}{ }^{-1}$ over the bark sample using a Mettler Toledo TGA1 device. The biomass was then pyrolyzed and the obtained biochar from this stage was used as a base matrix for developing the composite material. Total C, H, N, S, and $\mathrm{O}$ content in the base char was determined by a CHN Elemental analyzer (Costech ECS 4010). Moreover, the total P content was measured by the acid digestion procedure according to Kuo [20]. The basal spacing of the clay was determined with a Philips X'Pert MPD X-ray diffractometer with a Co-K $\alpha$ radiation source and scans were carried out for diffraction angels below $10^{\circ}$. The dispersion of chitosan among the clay platelets was also monitored optically using a transmission electron microscope (Zeiss EM 900) under an accelerating voltage of $80 \mathrm{kV}$. Ultra-Thin films $(<100 \mathrm{~nm})$ for this purpose were prepared by cutting from the epoxy block with the embedded nanocomposite sample at room temperature using a Leica Reichert OMU3 ultramicrotome. The Brunauer, Emmett, and Teller (BET) specific surface area and porosity were determined using a Belsorp mini II device. Surface morphology and elemental composition and distribution were observed over gold-coated samples using a Tescan MIRA3 LM FE-SEM equipped with a SAMx SDD energy dispersive detector. The FT-IR spectroscopy of the samples was conducted at room temperature with $\mathrm{KBr}$ pellets on a Bruker vertex70 FT-IR device.

The point of zero charge $\left(\mathrm{pH}_{\mathrm{PZC}}\right)$ of the MTCB was determined using the solid addition method [20,21]. $20 \mathrm{ml}$ of $0.01 \mathrm{M} \mathrm{KNO}_{3}$ was transferred to a series of $50 \mathrm{ml}$ flasks. The initial $\mathrm{pH}$ values $\left(\mathrm{pH}_{0}\right)$ of the series were adjusted in a 2-12 range by adding either $0.01 \mathrm{~N} \mathrm{HNO}_{3}$ or $\mathrm{NaOH}$. The final total volume of the solution in each flask was then exactly set to $25 \mathrm{ml}$ by adding the proper amount of $\mathrm{KNO}_{3}$ solution of the same ionic strength. After the $\mathrm{pH}_{0}$ of the solutions were accurately recorded, $0.1 \mathrm{~g}$ of MTCB was added to each flask which was immediately recapped. The suspensions were then intermittently shaken for $48 \mathrm{~h}$ to reach the equilibrium. Finally, the $\mathrm{pH}_{\mathrm{zpc}}$ was determined by plotting $\delta \mathrm{pH}$ (the difference between the initial $\mathrm{pH}_{0}$ and final $\mathrm{pH}_{\mathrm{f}}$ ) against the $\mathrm{pH}_{0}$, and designating the point of intersection in the resulting curve. The procedure was repeated for $0.1 \mathrm{M} \mathrm{KNO}_{3}$.

\section{Metal Adsorption Experiments in Aqueous Solution}

\section{Single-Element Batch Adsorption Experiments}

Individual stock solutions for $\mathrm{Cu}^{2+}, \mathrm{Pb}^{2+}$, and $\mathrm{Zn}^{2+}$ were prepared by dissolving proper amounts of their nitrate salts into $0.01 \mathrm{M} \mathrm{NaCl}$ as background electrolyte. Adsorption tests were conducted by agitating $0.25 \mathrm{~g}$ of MTCB sample in $25 \mathrm{ml}$ of single-element metal-containing solutions at $0.5,1$, $2,3,4,5,10,20,30,40,50$, and $51 \mathrm{mM}$ concentrations, for $24 \mathrm{~h}$ at different temperatures of 25,40 , and $60{ }^{\circ} \mathrm{C}$ until equilibrium was established. The $\mathrm{pH}$ of the system was adjusted at 5 by adding proper amount of diluted $\mathrm{HNO}_{3}$. At the end of each test, the suspension was filtered and the filtrate was acidified to $\mathrm{pH}<2$ for AAS analysis (Varian AA240, Australia). The residue was rinsed with DDW, dried and stored. Each test was duplicated and averaged. The amount of each metal uptake at equilibrium $q_{e}\left(\mathrm{mg} \mathrm{g}^{-1}\right)$ was calculated by:

$q_{e}=\left(C_{0}-C_{e}\right) V / W$

where $C_{0}$ and $C_{e}\left(\mathrm{mg} \mathrm{L}^{-1}\right)$ are initial $(\mathrm{t}=0)$ and equilibrium metal concentrations, respectively, $V$ is the volume of the solution (L) and $W$ is the used mass of dry MTCB (g).

A similar procedure was performed for batch kinetic experiments, repeating a $24 \mathrm{~h}$ adsorption test in case of $4 \mathrm{mM}$ concentration of each metal. Samples were withdrawn by removing $10 \mathrm{~mL}$ aliquots out of the initial $500 \mathrm{ml}$ solution at predetermined time intervals within the $24 \mathrm{~h}$. The amount of adsorbed metal at time $\mathrm{t}, q_{t}\left(\mathrm{mg} \mathrm{g}^{-1}\right)$, was calculated by:

$q_{t}=\left(C_{0}-C_{t}\right) \mathrm{V} / \mathrm{W}$ where $C_{t}\left(\mathrm{mg} \mathrm{L}^{-1}\right)$ is metal concentration at time t.

To evaluate and compare the adsorption capacities of $\mathrm{Cu}^{2+}, \mathrm{Zn}^{2+}$, and $\mathrm{Pb}^{2+}$ onto MTCB, the most common adsorption isotherm models namely Langmuir, Freundlich, Temkin, and Dubinin-Radushkevich (D-R) were used to analyze the experimental data (Table 1). In the Langmuir isotherm model is is assumed that adsorption occurs on homogeneous surface in monolayer coverage and no interaction between

Table 1 Isotherm functions and their parameters [23]

\begin{tabular}{|c|c|c|}
\hline Isotherm & Isotherm function & Parameters \\
\hline Langmuir & $q_{e}=\frac{Q_{\max } K_{L} C_{e}}{1+K_{L} C_{e}}$ & $\begin{array}{l}Q_{\max }\left(\mathrm{mg} \mathrm{g}^{-1}\right) \\
K_{L}\left(\mathrm{~L} \mathrm{mg}^{-1}\right)\end{array}$ \\
\hline Freundlich & $q_{e}=K_{F} C_{e}^{1 / n}$ & $\begin{array}{l}K_{F}\left(\mathrm{~L} \mathrm{mg}^{-1}\right)^{1 / n} \\
n\end{array}$ \\
\hline Temkin & $\begin{array}{l}q_{e}=\frac{R T}{b_{T}} \ln \left(K_{T} C_{e}\right) \\
Q_{\max }=\frac{R T}{b_{T}}\end{array}$ & $\begin{array}{l}Q_{\max }\left(\mathrm{mg} \mathrm{g}^{-1}\right) \\
K_{T}\left(\mathrm{~L} \mathrm{~g}^{-1}\right)\end{array}$ \\
\hline $\mathrm{D}-\mathrm{R}$ & $\begin{array}{l}q_{e}=Q_{\max } \exp \left(-D \varepsilon^{2}\right) \\
\varepsilon=R T \ln \left(1+\frac{1}{C_{e}}\right)\end{array}$ & $\begin{array}{l}Q_{\max }\left(\mathrm{mg} \mathrm{g}^{-1}\right) \\
D\left(\mathrm{~mol}^{2} \mathrm{~kJ}^{-2}\right)\end{array}$ \\
\hline
\end{tabular}


sorbed molecules. Also, a uniform energy of adsorption onto the surface and no transmigration of adsorbate in the surface plane are among the Langmuir model's assumptions. In the Freundlich model, multilayer adsorption on the heterogeneous solid surface of the adsorbent is assumed, where stronger binding sites are occupied first and the binding strength declines with increasing adsorbed quantity [22]. In the Temkin model, the decline of the heat of adsorption is not logarithmic [23] but linear as the adsorption proceeds towards the saturation point and the distribution of binding energy at all sites is uniform. In other words, it considers the effects of some indirect adsorbate/adsorbate interactions on the isotherm and suggests a linear decrease for heat of adsorption of all the molecules in the layer with coverage consequently [24]. The Dubinin-Radushkevich model is especially suitable for describing the adsorption onto porous materials.

In Table $1, q_{e}$ is the amount of the metal uptake per unit mass of MTCB ( $\left.\mathrm{mg} \mathrm{g}^{-1}\right), C_{e}$ is the equilibrium concentration of metal $\left(\mathrm{mg} \mathrm{L}^{-1}\right), Q_{\max }$ is the maximum loading capacity, $K_{L}$ is a constant related to the affinity, $K_{F}$ and $n$ are indicators of adsorption capacity and intensity in Freundlich isotherm, respectively. In the Temkin model, $K_{T}$ is the isotherm constant and $b_{T}$ is a constant related to heat of adsorption. Finally, in the D-R model, $D$ is the constant of the adsorption energy $\left(\mathrm{mol}^{2} \mathrm{~kJ}^{-2}\right)$, which is related to the average energy of adsorption per unit mole of the adsorbate, energy needed for the transfer from infinite distance to the surface of the adsorbent, and $\varepsilon$ is the Polanyi potential. $T$ is absolute solution temperature $(\mathrm{K})$ and $R$ is the universal gas constant (equal to $8.314 \mathrm{~J} \mathrm{~mol}^{-1} \mathrm{~K}^{-1}$ ).

Application of D-R isotherm helps determine the chemical or physical nature of the adsorption process. The value of mean adsorption energy, $E\left(\mathrm{~kJ} \mathrm{~mol}^{-1}\right)$, can be obtained from D-R parameter $D$ using the following equation

$E=\frac{1}{\sqrt{2 D}}$

The value of $E$ ranges from 1 to $8 \mathrm{~kJ} \mathrm{~mol}^{-1}$ in case of physical adsorption to $8-16 \mathrm{~kJ} \mathrm{~mol}^{-1}$ for chemical adsorption [25].

Isotherm parameters are determined through non-linear regression, setting the average relative error $(A R E)$ to zero if using the Solver add-in function of Microsoft Excel. The $A R E$ has been calculated between experimental and calculated values and is given in

$A R E=\frac{100}{n} \sum_{i=1}^{n}\left|\frac{q_{e \text { calc }}-q_{e} \exp }{q_{e \exp }}\right|_{i}$

where $q_{e \text { calc }}$ and $q_{e \text { exp }}$ are calculated and experimental equilibrium capacity, respectively, and $n$ is the number of experiments. Obviously, lower $A R E$ represents the best fit model.

The rate-controlling steps during the adsorption of each metal were further identified by kinetic studies. In this regard, second order, pseudo-second order, Elovich and intra-particle diffusion kinetic models were applied (Table 2). The best-fit kinetic model was obtained by nonlinear regression method with the lowest $A R E$ value.

\section{Multi-Element Batch Adsorption Experiment}

A suspension of $10 \mathrm{~g} \mathrm{~L}^{-1}$ MTCB in background electrolyte $(0.01 \mathrm{M} \mathrm{NaCl})$ was prepared and equilibrated for $24 \mathrm{~h}$. After pH measurement (Metrohm $827 \mathrm{pH}$ lab, Switzerland), $\mathrm{Cu}^{2+}, \mathrm{Zn}^{2+}$, and $\mathrm{Pb}^{2+}$ (as their nitrate salts) were added simultaneously, so that the final concentration of each metal in the reactor reached $4 \mathrm{mM}$. The reactor was agitated for another $24 \mathrm{~h}$ and after $\mathrm{pH}$ measurement, the suspension was filtered and the filtrate was acidified to $\mathrm{pH}<2$ for AAS analysis. The experiment was duplicated and averaged. All the tests were performed at room temperature.

\section{Immobilization of $\mathrm{Cu}^{2+}, \mathrm{Pb}^{2+}$, and $\mathrm{Zn}^{2+}$ in Soil}

Synthetic rain water (SRW) was prepared by adding a diluted sulfuric/nitric acid mixture $(60 / 40 \mathrm{w} / \mathrm{w})$ to DDW until pH 4.2 according to EPA method 1312. The synthetic precipitation leaching procedure (SPLP) was performed as $10 \mathrm{~g}$ of the soil sample amended with $10 \%$ MTCB ( $\mathrm{w}_{\text {char }} /$ $\left.\mathrm{w}_{\text {soil }}\right)$ was equilibrated in SRW $\left(20 \mathrm{~g} \mathrm{~L}^{-1}\right)$ for $24 \mathrm{~h}$ in an end-over-end shaker. After pH measurement, $\mathrm{Cu}^{2+}, \mathrm{Zn}^{2+}$, and $\mathrm{Pb}^{2+}$ (again as their nitrate salts) were added simultaneously for the final concentration of $4 \mathrm{mM}$ for each metal. The reactor was agitated for another $24 \mathrm{~h}$, the $\mathrm{pH}$ was measured, the suspension was centrifuged, the supernatant was filtered, and the filtrate was acidified to $\mathrm{pH}<2$ for AAS analysis.

Table 2 Kinetic models and their parameters

\begin{tabular}{llll}
\hline Kinetic model & Equation & Parameters & Ref. \\
\hline Second order & $q_{t}=q_{e} /\left(1+q_{e} k_{2} t\right)$ & $\begin{array}{l}q_{e}\left(\mathrm{mg} \mathrm{g}^{-1}\right) \\
k_{2}\left(\mathrm{~g} \mathrm{mg}^{-1} \mathrm{~h}^{-1}\right)\end{array}$ & [23] \\
Pseudo-second & $q_{t}=k_{2 P} q_{e}^{2} t /\left(1+q_{e} k_{2 P} t\right)$ & $q_{e}\left(\mathrm{mg} \mathrm{g}^{-1}\right)$ & \\
$k_{2 P}\left(\mathrm{~h}^{-1}\right)$ & \\
order & & $\beta\left(\mathrm{mg}^{-1}\right)$ & \\
Elovich & $q_{t}=\frac{1}{\beta} \ln (\alpha \beta t)$ & $\alpha\left(\mathrm{mg} \mathrm{g}^{-1} \mathrm{~h}^{-1}\right)$ & \\
& & $k_{i d}\left(\mathrm{mg} \mathrm{g}^{-1} \mathrm{~h}^{-0.5}\right)$ & \\
Intra-particle & $q_{t}=k_{i d} t / 2+I$ & & \\
diffusion & &
\end{tabular}




\section{Results and Discussion}

\section{Determination of the Proper Pyrolysis Conditions}

The biomass was initially subjected to the thermal analysis. Result of TGA over the bark chips is shown in Fig. 1. According to the results, the initial mass loss was approximately $10 \%$ and mainly due to moisture evaporation. Devolatilization and biomass thermal decomposition were responsible for most of the loss of mass (approximately 70\%). The same mass loss steps may be deducted based on the obvious peak values in DTA curve. It should be noted that the characteristic thermal decomposition of hemicellulose, cellulose and lignin, as the main constituent of the biomass, are reported to be at 200-350, 320-400, and $250-550{ }^{\circ} \mathrm{C}$, respectively [26]. Accordingly, the pyrolysis conditions were selected as $600{ }^{\circ} \mathrm{C}$ at $10^{\circ} \mathrm{C} \mathrm{m^{-1 }}$ and $2 \mathrm{~h}$ residence time, which made the char more recalcitrant, by degrading the main biopolymers and increasing the number of aromatic compounds.

\section{Characterization of the Base Biochar}

The obtained char was analyzed for its $\mathrm{C}, \mathrm{H}, \mathrm{N}, \mathrm{S}, \mathrm{O}$, and $\mathrm{P}$ content (Table 3 ). The $\mathrm{O} / \mathrm{C}$ and $\mathrm{H} / \mathrm{C}$ ratios are $<0.2$ and $<0.4$, respectively, which indicates that the obtained biochar has high carbon sequestration potential [27].

FE-SEM micrographs reveal the nanoporous texture for the biochar (Fig. 2a). This was also confirmed by the value of the mean pore diameter obtained by BET analysis

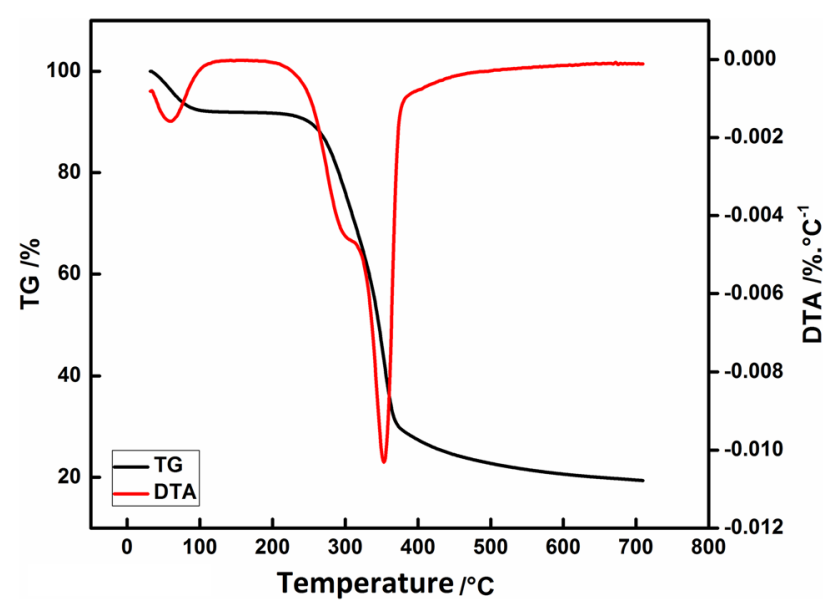

Fig. 1 Thermogravimetric and derivative thermogravimetric mass loss curves
(Table 4), since the high value of the total surface area also indicates a highly porous matrix for the pristine biochar. The nitrogen adsorption-desorption isotherm (Fig. 2b) shows a dramatic rise in $\mathrm{N}_{2}$ adsorption at relative pressures less than 0.1 , which is due to the presence of micropores (pores with diameters up to $2 \mathrm{~nm}$ ) [28]. At higher relative pressures, the adsorption of the gas into mesopores (pores with diameters within 2-50 nm) of biochar occurs where along with the formation of multimolecular layers, condensation of the gaseous molecules takes place in what is called capillary condensation [28]. The shape of adsorption isotherms can provide qualitative information on the adsorption process and the extent of the surface area available to the adsorbate. The experimental isotherm follows a combination of type I and IV with a mixed micro/ mesoporous structure, according to the IUPAC classification [29]. Various data could be calculated using different analysis methods such as BJH and t-plot (Table 4). These data confirm that the microporosity in the biochar is high enough to be used as a base matrix in the nanocomposite adsorbent. The BJH pore distribution is also given in Fig. 2b.

\section{Characterization of the Final Hybrid}

A chitosan/clay/biochar nanobiohybrid (MTCB) was designed and developed and resulted in a composite with the simultaneous advantage of the chelating behavior of chitosan, the lamellar adsorptive properties of clay (MT), and the nanoporosity of the base biochar.

XRD is a useful method for investigating the mode of MT and chitosan engagement (e.g. tactoids, intercalation, or exfoliation) [8]. Figure 3 a illustrates a comparison between X-ray diffraction patterns of MT and MTCB. The XRD pattern of MT shows a reflection at $2 \theta=8.88^{\circ}$ for the basal 001 lattice spacing of silicate layer, whereas there is no characteristic reflection in the pattern related to MTCB. This possibly confirms the formation of a partial exfoliated MT dispersion in the chitosan matrix [30]. In fact, the poly-cationic nature of chitosan enables its easy adsorption onto the negatively charged layers of MT. in this process, the intrusion of chitosan into clay interlayer spaces forces the platelets apart, increasing the d-value. This process may continue until the platelets are completely separated and distributed within the chitosan matrix [31]. However, definitive conclusions on the basis of XRD alone about the structure may not suffice [8] and TEM techniques are
Table 3 Elemental composition of the pristine biochar

\begin{tabular}{lllllll}
\hline Element & $\mathrm{C}$ & $\mathrm{H}$ & $\mathrm{N}$ & $\mathrm{S}$ & $\mathrm{O}$ & $\mathrm{P}$ \\
\hline Mass percent & 77.74 & 1.92 & 0.66 & 0.55 & 11.15 & 0.134 \\
\hline
\end{tabular}



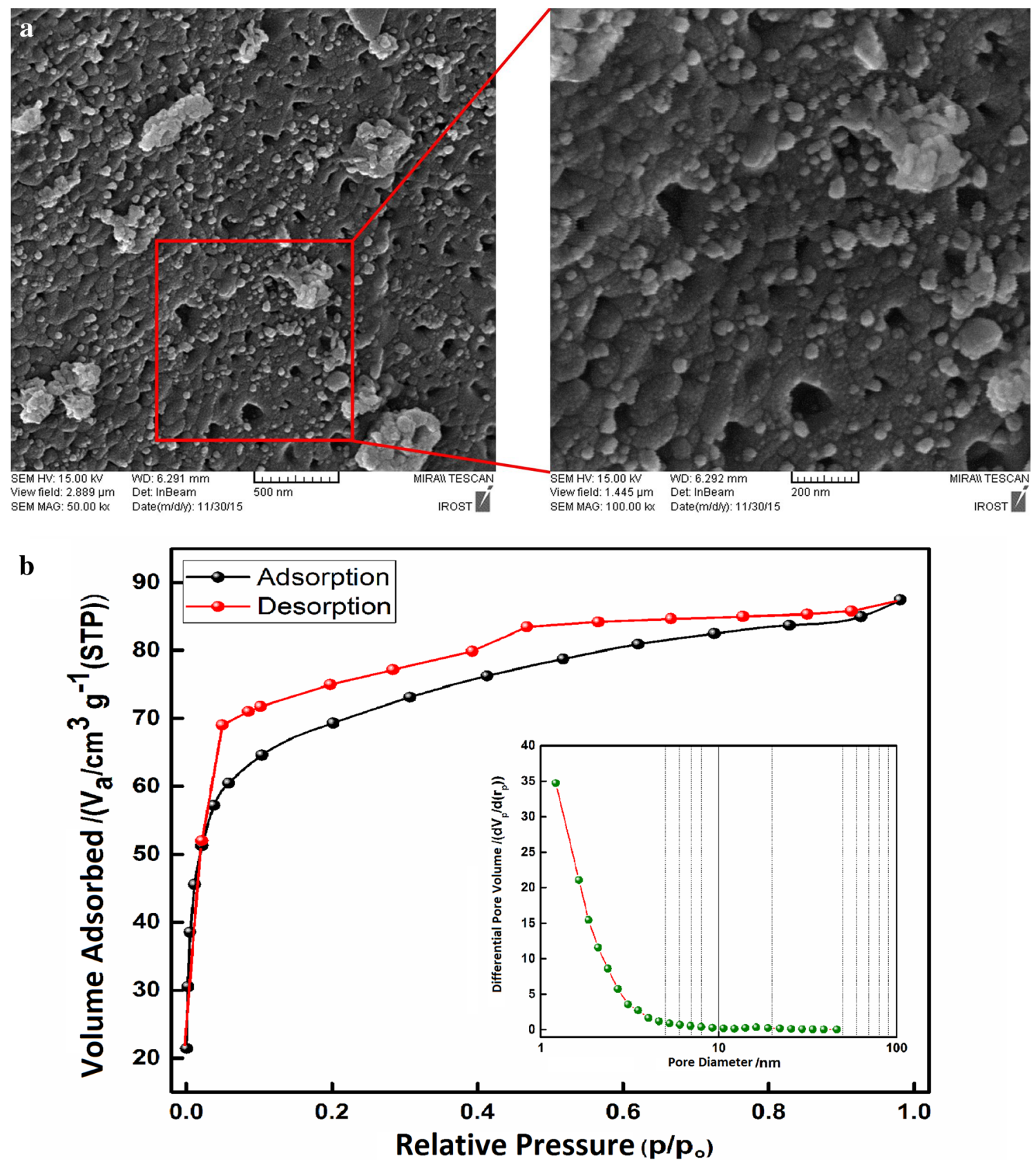

Fig. 2 FE-SEM micrographs (a), and adsorption-desorption diagram and BJH pore volume distribution (b) (adsorbate: $\mathrm{N}_{2}$, adsorption temperature: $77 \mathrm{~K}$ ) of the pristine biochar sample

Table 4 Parameter values obtained from the nitrogen adsorption isotherm

\begin{tabular}{lllll}
\hline $\begin{array}{l}\text { Total sur- } \\
\text { face area/ } \\
\left(\mathrm{m}^{2} \mathrm{~g}^{-1}\right)\end{array}$ & $\begin{array}{l}\text { Mean pore } \\
\text { diameter } / \\
\mathrm{nm}\end{array}$ & $\begin{array}{l}\text { Total pore } \\
\text { volume/ } \\
\left(\mathrm{cm}^{3} \mathrm{~g}^{-1}\right)\end{array}$ & $\begin{array}{l}\text { Micropore } \\
\text { volume } \\
\left(\mathrm{cm}^{3} \mathrm{~g}^{-1}\right)\end{array}$ & $\begin{array}{l}\text { Mesopore } \\
\text { volume } \\
\left(\mathrm{cm}^{3} \mathrm{~g}^{-1}\right)\end{array}$ \\
\hline 272.49 & 1.9842 & 0.1352 & 0.1262 & $5.0116 \times 10^{-2}$ \\
\hline
\end{tabular}

${ }^{\mathrm{a} C a l c u l a t e d}$ from t-plot

${ }^{\mathrm{b}}$ Calculated from BJH also necessary for characterizing the morphology of the MTCB. TEM images show the perfect dispersion of MT in the chitosan matrix so that mixed intercalated and exfoliated structures were obtained (Fig. 3b).

FE-SEM micrographs also show three different phases indicating the heterogeneous structure of the MTCB (Fig. 4a, b) comprising the flaky amorphous nature of chitosan [17], the porous structure of the biochar, and the curly and delaminated sheets of nanoclay [32] with much smaller sizes scattered within the chitosan. The amount of 


\section{$\mathbf{a}$}

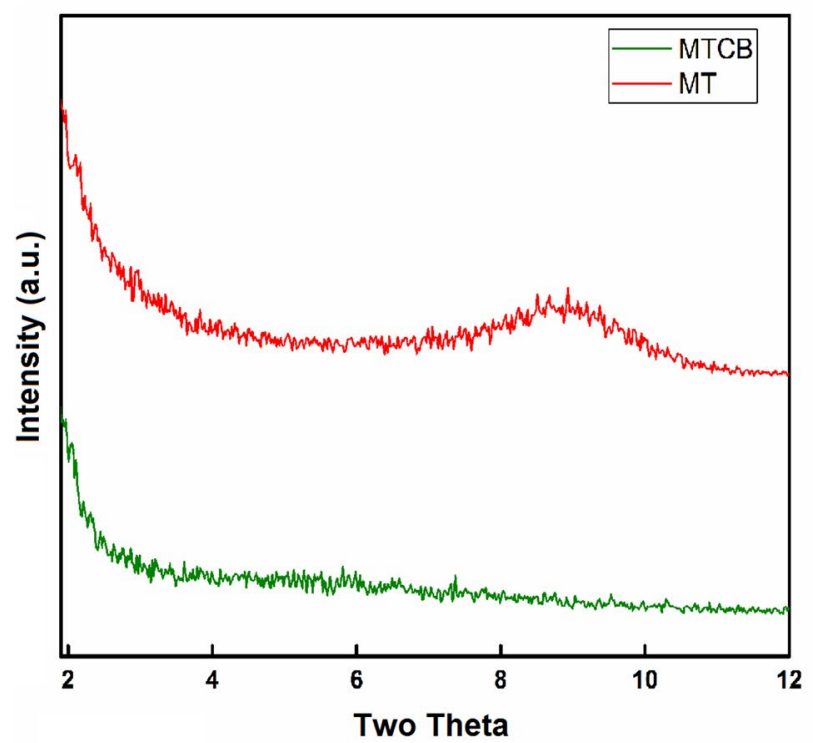

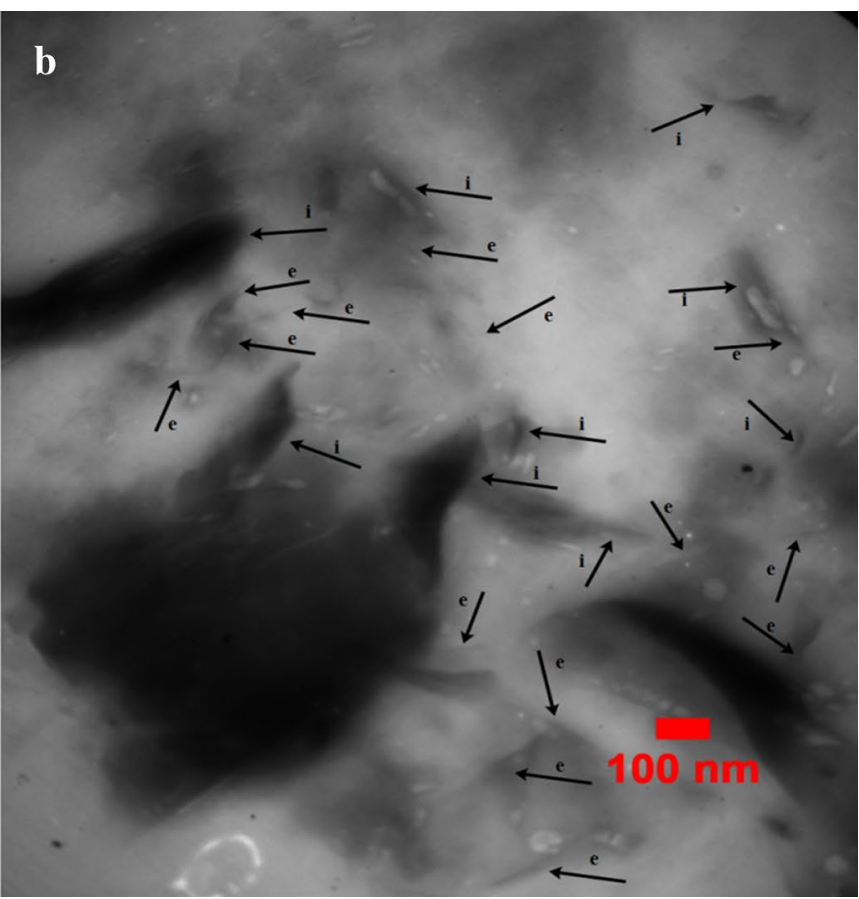

Fig. 3 a Comparison of XRD patterns related to the original Cloisite- $\mathrm{Na}^{+}(\mathrm{MT})$ and the clay/chitosan/biochar nanobiocomposite (MTCB), and b TEM micrograph showing the intercalated (i) and exfoliated (e) silicate layers appearing as sharp lines on a grey background from the matrix

Fig. 4 FE-SEM micrographs (a and $\mathbf{b})$ and EDS analysis (c) of MTCB (outstanding peak of Au is related to the sputtered gold layer during preparation step)
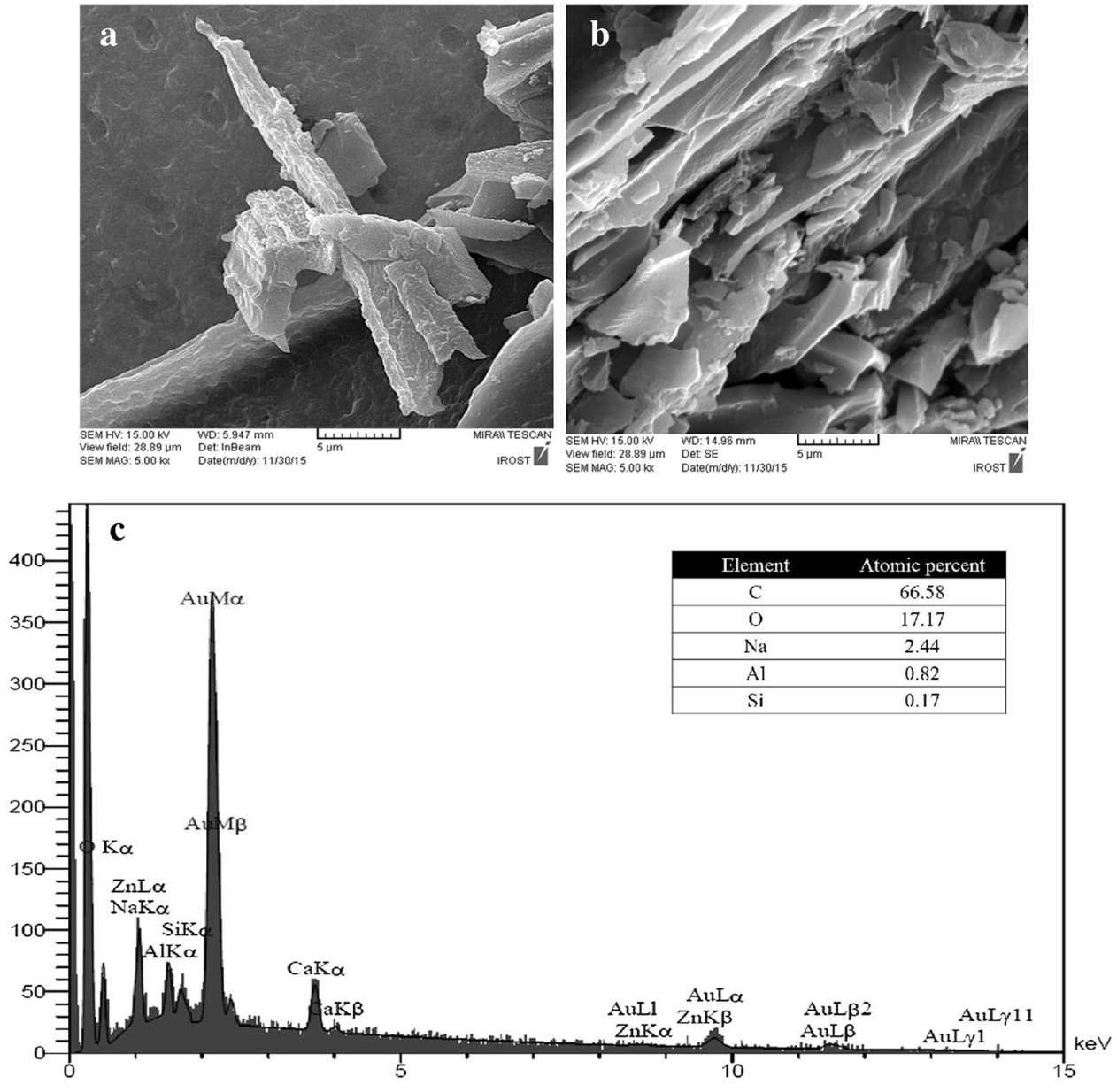
$\mathrm{Si}, \mathrm{Al}$, and $\mathrm{Na}$ may represent the dispersed Na-clay particles within the matrix (Fig. 4c). The strong interaction between the matrix and silicate layers in MTCB are due to the hydrogen bonds formed between amino and hydroxyl functional groups in each chitosan unit and the silicate hydroxylated edge groups [8].

Active functional groups present on the MTCB surface are evaluated by studying the FT-IR spectrum. Figure 5 shows the spectra of pure chitosan (PC) and MTCB for comparison. In the FT-IR spectrum of PC, the bands near $3300 \mathrm{~cm}^{-1}$ are attributed to stretching vibrations of the $\mathrm{O}-\mathrm{H}$ and $\mathrm{N}-\mathrm{H}$ groups, whereas those near $2900 \mathrm{~cm}^{-1}$ correspond to aliphatic $\mathrm{C}-\mathrm{H}$ stretching vibrations. Additionally, the band at $1648 \mathrm{~cm}^{-1}$ corresponds to the protonated amine group in chitosan, while the one at $1561 \mathrm{~cm}^{-1}$ corresponds to the $-\mathrm{NH}_{2}$ band. The bands near $1400 \mathrm{~cm}^{-1}$ can be attributed to deformation vibrations of aliphatic $\mathrm{C}-\mathrm{H}$ groups. The spectrum of MTCB sample shows the combination of characteristic bands due to chitosan and clay. The shifting of the $\mathrm{N}-\mathrm{H}$ deformation band from $1561 \mathrm{~cm}^{-1}$ in pure chitosan to $1660 \mathrm{~cm}^{-1}$ in MTCB indicated the interaction of the negatively charged MT surfaces with the protonated amine groups $\left(-\mathrm{NH}_{3}{ }^{+}\right)$of chitosan. The bands corresponding to the $\mathrm{C}-\mathrm{H}$ deformation modes of chitosan were also shifted as a result of the chitosan-clay layers interactions.

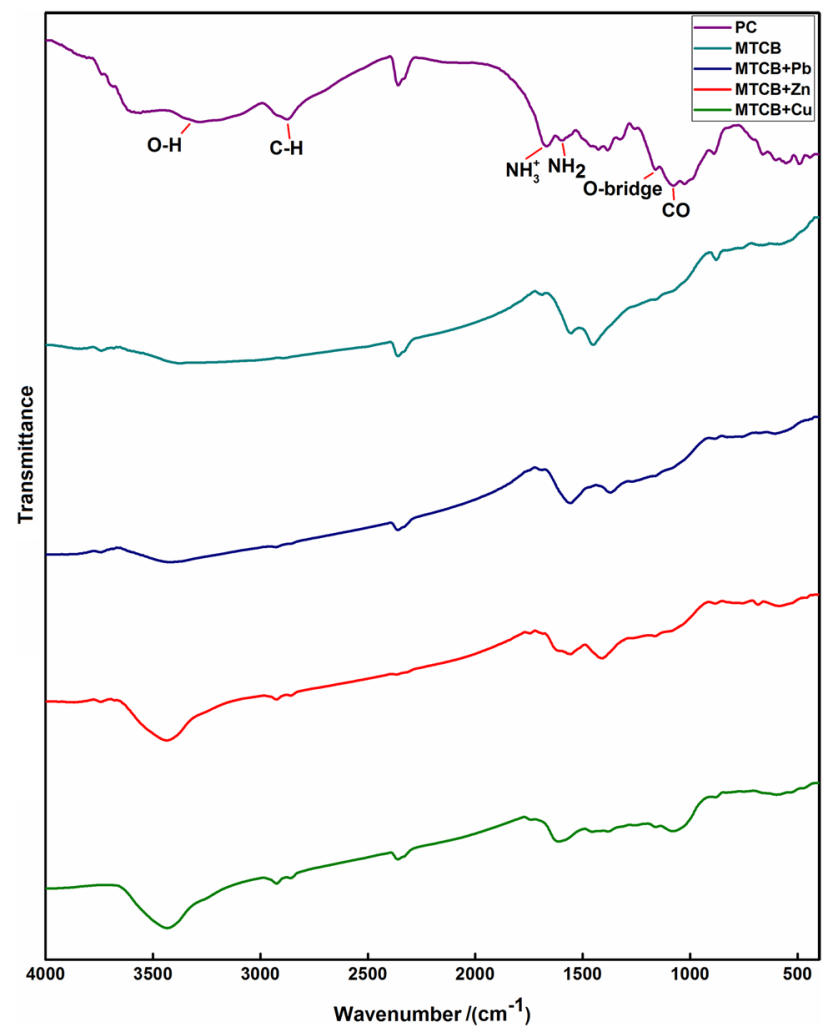

Fig. 5 FT-IR spectra of PC and MTCB (pre and post sorption samples)

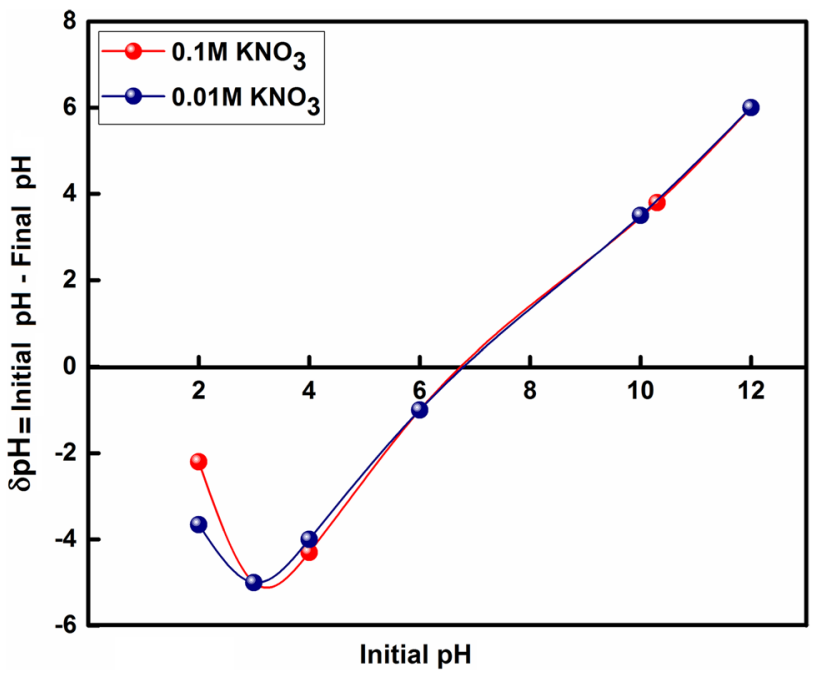

Fig. 6 Point of zero charge $\left(\mathrm{pH}_{\mathrm{PZC}}\right)$ of MTCB

The point of zero charge was determined by the solid addition method. Figure 6 represents the plot of $\delta \mathrm{pH}$ versus initial $\mathrm{pH}$ value for the MTCB at two different $\mathrm{KNO}_{3}$ concentrations of 0.01 and $0.1 \mathrm{M}$. The intersection point of both curves with the horizontal axis obviously coincide at $\mathrm{pH} 6.8$. This indicates that $\mathrm{pH}_{\mathrm{PZC}}$ for MTCB is at $\mathrm{pH} 6.8$.

\section{Single-Element Batch Adsorption Experiments}

Figure 7 shows the results of single-element batch adsorption tests done for the 12 different initial concentrations. The loading capacity increased as higher initial concentration was used in experiments and finally leveled off at $50 \mathrm{mM}$ concentration. This implies that the maximum sorption capacity of the nanocomposite at $25^{\circ} \mathrm{C}$ for copper, lead and zinc is $121.5,336$, and $134.6 \mathrm{mg} \mathrm{g}^{-1}$, respectively. According to Fig. 7, a higher temperature favored metal ions adsorption onto MTCB suggesting that the adsorption onto MTCB was an endothermic process enabling the metal ions to overcome the diffuse double layer and adsorb onto the composite's interior structure provided the sufficient energy at elevated temperatures. Earlier research [31, 32] suggested the same. Table 5 lists the details of isotherms fitting data. According to the $A R E$ values, sorption of copper and zinc onto MTCB is in agreement with the Freundlich, isotherm while lead sorption isotherm is better described by the Temkin model.

The kinetic data obtained from single-element batch reactor tests are also shown in Fig. 8a. Non-linear regression of the kinetics of copper, zinc, and lead sorption onto MTCB composite are best described by the pseudo-second order model (Table 6). Such a kinetic model agrees well with the occurrence of both chemical reaction and physical diffusion process $[33,34]$. 

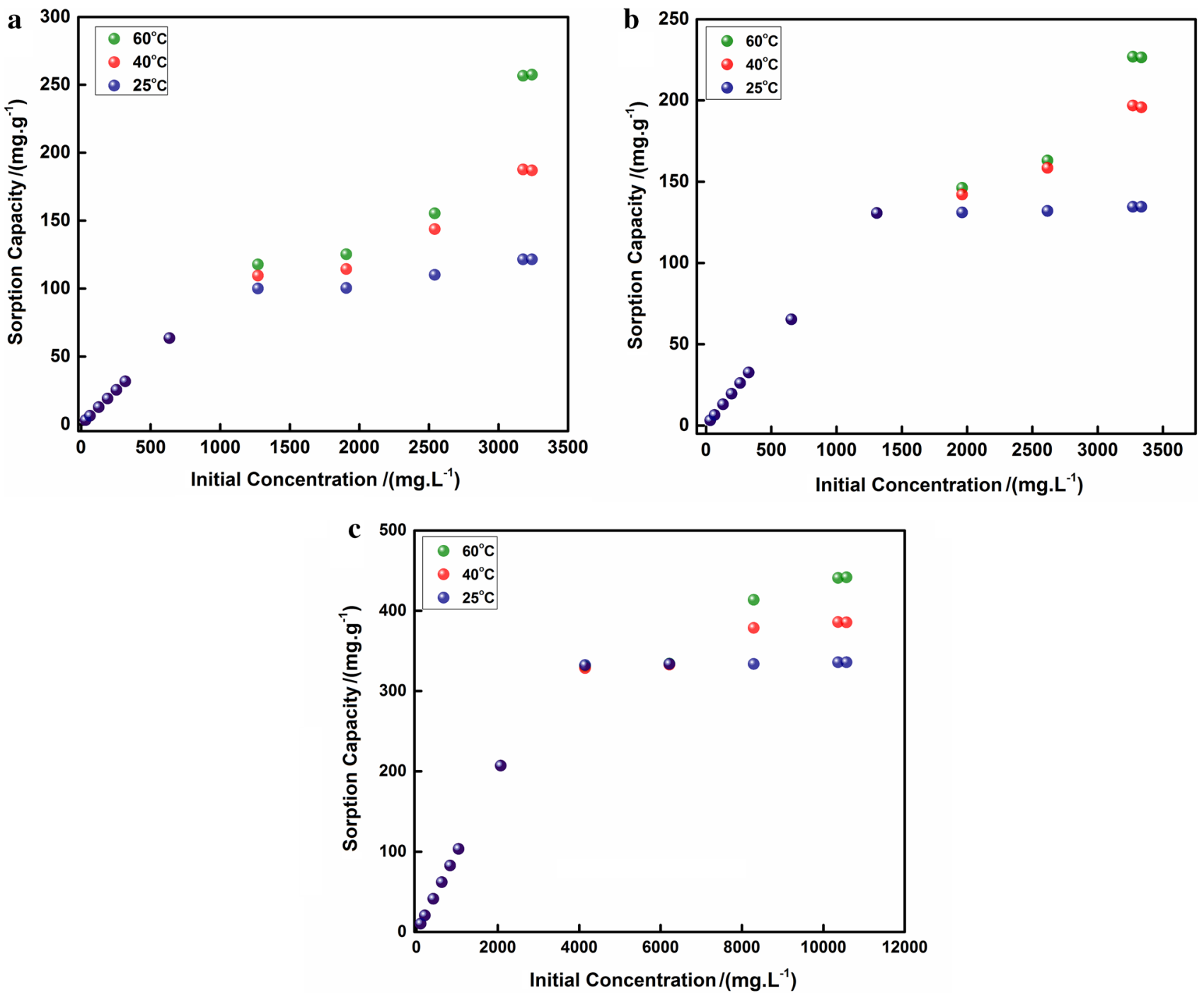

Fig. 7 Individual variations of a copper, $\mathbf{b}$ zinc, and $\mathbf{c}$ lead sorption capacity against initial metal concentration for different temperatures (25, 40 , and $60^{\circ} \mathrm{C}$ )

Table 5 Constants and ARE of langmuir, freundlich, temkin and D-R models for $\mathrm{Cu}^{2+}, \mathrm{Zn}^{2+}$, and $\mathrm{Pb}^{2+}$ adsorption onto MTCB (adsorbent dose $\left.10 \mathrm{~g} \mathrm{~L}^{-1}\right)$

\begin{tabular}{|c|c|c|c|c|c|c|c|c|}
\hline \multirow[t]{3}{*}{ Heavy metal } & \multicolumn{8}{|l|}{ Isotherm model } \\
\hline & \multicolumn{2}{|l|}{ Langmuir } & \multicolumn{2}{|l|}{ Freundlich } & \multicolumn{2}{|l|}{ Temkin } & \multicolumn{2}{|l|}{ D-R } \\
\hline & Parameters & $A R E$ & Parameters & $A R E$ & Parameters & $A R E$ & Parameters & $A R E$ \\
\hline $\mathrm{Cu}^{2+}$ & $\begin{array}{l}Q_{\max }=115.48 \mathrm{mg} \mathrm{g}^{-1} \\
K_{L}=0.0240 \mathrm{~L} \mathrm{mg}^{-1}\end{array}$ & 5.11 & $\begin{array}{l}K_{F}=58.38\left(\mathrm{~L} \mathrm{mg}^{-1}\right)^{1 / n} \\
n=10.39\end{array}$ & 3.78 & $\begin{array}{l}K_{T}=31.23 \mathrm{~L} \mathrm{~g}^{-1} \\
Q_{\max }=10.99 \mathrm{mg} \mathrm{g}^{-1}\end{array}$ & 4 & $\begin{array}{l}Q_{\max }=121.87 \mathrm{mg} \mathrm{g}^{-1} \\
D=0.001 \mathrm{~mol}^{2} \mathrm{~kJ}^{-2}\end{array}$ & 5.83 \\
\hline $\mathrm{Zn}^{2+}$ & $\begin{array}{l}Q_{\max }=136.33 \mathrm{mg} \mathrm{g}^{-1} \\
K_{L}=0.0391 \mathrm{~L} \mathrm{mg}^{-1}\end{array}$ & 0.3288 & $\begin{array}{l}K_{F}=112.39\left(\mathrm{~L} \mathrm{mg}^{-1}\right)^{1 / n} \\
n=42.11\end{array}$ & 0.2704 & $\begin{array}{l}K_{T}=1.04 \times 10^{15} \mathrm{~L} \mathrm{~g}^{-1} \\
Q_{\text {max }}=3.19 \mathrm{mg} \mathrm{g}^{-1}\end{array}$ & 0.2774 & $\begin{array}{l}Q_{\max }=135.02 \mathrm{mg} \mathrm{g}^{-1} \\
D=0.002 \mathrm{~mol}^{2} \mathrm{~kJ}^{-2}\end{array}$ & 0.40 \\
\hline $\mathrm{Pb}^{2+}$ & $\begin{array}{l}Q_{\max }=334.5 \mathrm{mg} / \mathrm{g} \\
K_{L}=0.1933 \mathrm{~L} \mathrm{mg}^{-1}\end{array}$ & 1.18 & $\begin{array}{l}K_{F}=321.90\left(\mathrm{~L} \mathrm{mg}^{-1}\right)^{1 / n} \\
n=217.42\end{array}$ & 0.7667 & $\begin{array}{l}K_{T}=9.42 \times 10^{89} \mathrm{~L} \mathrm{~g}^{-1} \\
Q_{\text {max }}=1.55 \mathrm{mg} \mathrm{g}^{-1}\end{array}$ & 0.1408 & $\begin{array}{l}Q_{\max }=336.05 \mathrm{mg} \mathrm{g}^{-1} \\
D=0.0012 \mathrm{~mol}^{2} \mathrm{~kJ}^{-2}\end{array}$ & 1.54 \\
\hline
\end{tabular}



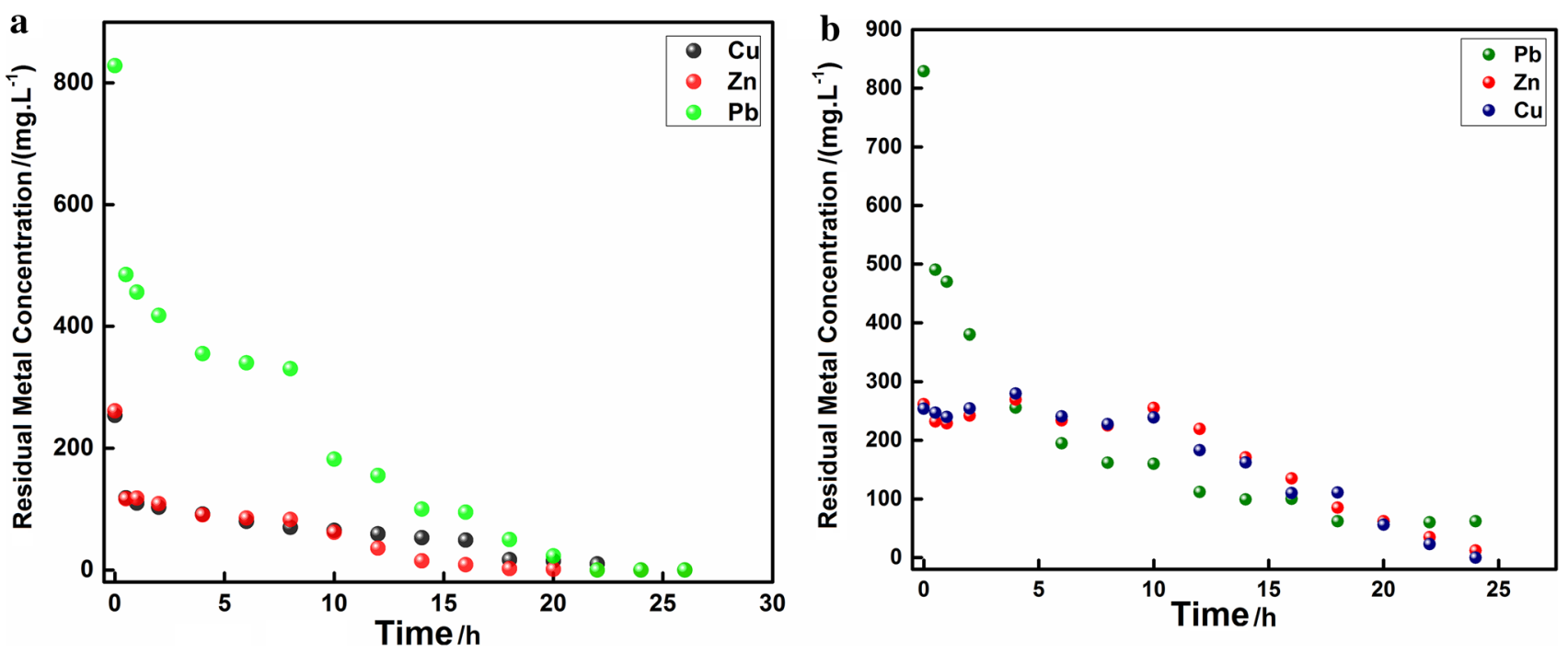

Fig. 8 Variations of residual concentration in a single-element and $\mathbf{b}$ multi-element metal solutions (conditions: initial concentration: $4 \mathrm{mM}$, adsorbent dose $10 \mathrm{~g} \mathrm{~L}^{-1}$, Temperature: $25^{\circ} \mathrm{C}$ )

Table 6 Constants and ARE of Elovich, second order, and pseudo-second order kinetic models (initial concentration: $4 \mathrm{mM}$, adsorbent dose $10 \mathrm{~g} \mathrm{~L}^{-1}$ )

\begin{tabular}{|c|c|c|c|c|c|c|}
\hline \multirow[t]{3}{*}{ Heavy metal } & \multicolumn{6}{|l|}{ Kinetic model } \\
\hline & \multicolumn{2}{|l|}{ Elovich } & \multicolumn{2}{|l|}{ Second order } & \multicolumn{2}{|c|}{ Pseudo-second order } \\
\hline & Parameters & $A R E$ & Parameters & $A R E$ & Parameters & $A R E$ \\
\hline $\mathrm{Cu}^{2+}$ & $\begin{array}{l}\alpha=435.76 \mathrm{mg} \mathrm{g}^{-1} \mathrm{~h}^{-1} \\
\beta=0.3110 \mathrm{~g} \mathrm{mg}^{-1}\end{array}$ & 3.17 & $\begin{array}{l}\mathrm{q}_{\mathrm{e}}=16.92 \mathrm{mg} \mathrm{g}^{-1} \\
\mathrm{k}_{2}=-0.001 \mathrm{~g} \mathrm{mg}^{-1} \mathrm{~h}^{-1}\end{array}$ & 10.95 & $\begin{array}{l}\mathrm{q}_{\mathrm{e}}=26.09 \mathrm{mg} \mathrm{g}^{-1} \\
\mathrm{k}_{2 \mathrm{P}}=0.0560 \mathrm{~h}^{-1}\end{array}$ & 5.25 \\
\hline $\mathrm{Zn}^{2+}$ & $\begin{array}{l}\alpha=565.70 \mathrm{mg} \mathrm{g}^{-1} \mathrm{~h}^{-1} \\
\beta=0.3173 \mathrm{~g} \mathrm{mg}^{-1}\end{array}$ & 4.40 & $\begin{array}{l}\mathrm{q}_{\mathrm{e}}=16.86 \mathrm{mg} \mathrm{g}^{-1} \\
\mathrm{k}_{2}=-0.001 \mathrm{~g} \mathrm{mg}^{-1} \mathrm{~h}^{-1}\end{array}$ & 8.53 & $\begin{array}{l}\mathrm{q}_{\mathrm{e}}=27.34 \mathrm{mg} \mathrm{g}^{-1} \\
\mathrm{k}_{2 \mathrm{P}}=0.0313 \mathrm{~h}^{-1}\end{array}$ & 8.73 \\
\hline $\mathrm{Pb}^{2+}$ & $\begin{array}{l}\alpha=177.02 \mathrm{mg} \mathrm{g}^{-1} \mathrm{~h}^{-1} \\
\beta=0.066 \mathrm{~g} \mathrm{mg}^{-1}\end{array}$ & 19.34 & $\begin{array}{l}\mathrm{q}_{\mathrm{e}}=42.74 \mathrm{mg} \mathrm{g}^{-1} \\
\mathrm{k}_{2}=-0.0006 \mathrm{~g} \mathrm{mg}^{-1} \mathrm{~h}^{-1}\end{array}$ & 10.03 & $\begin{array}{l}\mathrm{q}_{\mathrm{e}}=90.62 \mathrm{mg} \mathrm{g}^{-1} \\
\mathrm{k}_{2 \mathrm{P}}=0.0053 \mathrm{~h}^{-1}\end{array}$ & 7.28 \\
\hline
\end{tabular}

It is also possible to evaluate the sorption kinetics from a mechanistic point of view [35, 36]. The overall adsorption process is controlled either by one or more steps (e.g. film diffusion, pore diffusion, etc.) and at a high stirring rate, the diffusive mass transfer with one apparent diffusion coefficient may fit the experimental sorption kinetic data. For an exact surface adsorption, rate variations should be proportional to the first power of concentration; however, when pore diffusion limits adsorption, the relationship between initial solute concentration and the rate of adsorption may become nonlinear [37]. The possibility of intra-particle diffusion can be explored by applying the intra-particle diffusion model (Table 2) to the kinetic data [38]. Values of $I$ is attributed to the thickness of the boundary layer and its effect is larger in case of greater intercepts. By applying this model, the data are related by two straight lines (Fig. 9). The deviation of the straight line is the result of the difference in the rate of mass transfer in the initial and final stages of

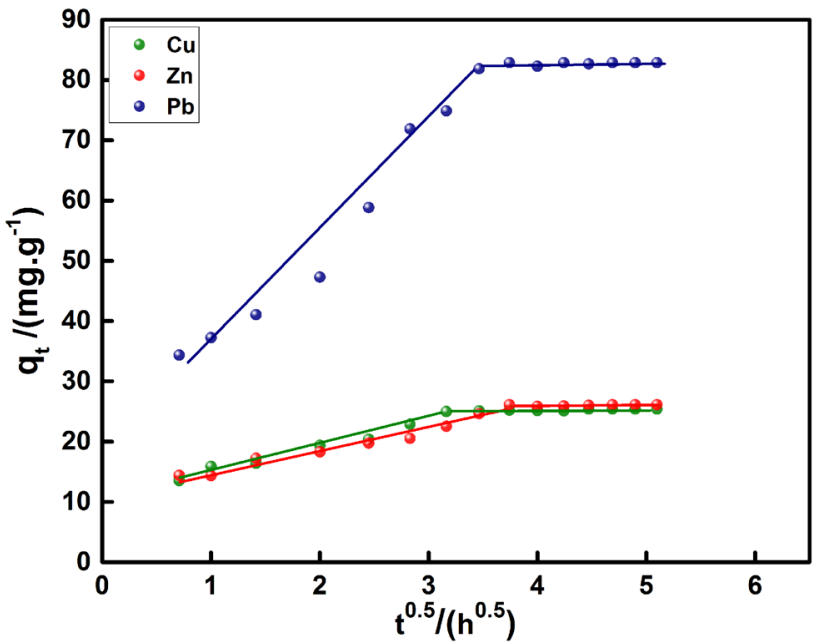

Fig. 9 Weber and Morris intra-particle diffusion plot for sorption of copper, zinc and lead by MTCB $\left(\mathrm{pH}_{0}=5, \mathrm{~T}=25{ }^{\circ} \mathrm{C}\right.$, adsorbent dose $=10 \mathrm{~g} \mathrm{~L}^{-1}, \mathrm{C}_{0}=4 \mathrm{mM}$ ) 
sorption process; the first line depicts the diffusion in the macropores while the second represents the micropore diffusion. Obviously, $\mathrm{Pb}^{2+}$ has larger value of $K_{i d}$ (the slope of first line) for diffusion into the porosity which can explain the higher affinity of MTCB for Pb-sorption in comparison with sorption of $\mathrm{Cu}^{2+}$ and $\mathrm{Zn}^{2+}$.

\section{The Sorption Mechanisms}

Since the $\mathrm{pH}_{\mathrm{pzc}}$ of MTCB is 6.8, in acidic media, the surface charge of MTCB is positive and this is not in favour of physical adsorption. According to the D-R model and by calculating the mean energy of adsorption $(E), \mathrm{Cu}^{2+}, \mathrm{Zn}^{2+}$, and $\mathrm{Pb}^{2+}$ sorption result in values that are usually attributed to chemisorption $\left(20.64,16\right.$, and $20.43 \mathrm{Kj} \mathrm{mol}^{-1}$, respectively).

To be more precise, the FT-IR spectra were obtained for metal-loaded MTCB. The post-sorption FT-IR spectrum shows that the wavenumber and intensity of some peaks are shifted to lower values in comparison with the pre-sorption MTCB sample. This suggests that certain functional groups related to the wavenumbers involved play a role in immobilization of metals onto the composite material. In all three loaded samples, the $-\mathrm{NH}_{2}$ group is involved in the binding of metals, mitigating and shifting the $\mathrm{N}-\mathrm{H}$ band in MTCB (Fig. 5). Hence, also FT-IR spectra confirm the chemisorption mechanism in case of each metal.

\section{Multi-Element Batch Adsorption Experiments}

The simultaneous immobilization of $\mathrm{Cu}^{2+}, \mathrm{Zn}^{2+}$, and $\mathrm{Pb}^{2+}$ onto MTCB was investigated for the initial concentration of $4 \mathrm{mM}$ for each metal (Fig. 8b). Table 7 represents a comparison for the co-sorption capacity ( of $\mathrm{Cu}, \mathrm{Pb}$, and $\mathrm{Zn}$ ) between the base char and MTCB. Obviously, as for equal moles of adsorbents, both base char and MTCB show higher affinity for lead ions. This is also confirmed in the metal distribution pattern obtained in post-sorption specimens using EDS mapping (Fig. 10) where the denser map of Fig. 10c indicates the larger amount of immobilized $\mathrm{Pb}^{2+}$ over the MTCB specimen.

Table 7 Comparison of the simultaneous adsorption capacity between the pristine biochar and MTCB (initial metal concentration: $4 \mathrm{mM}$, adsorbent dose: $10 \mathrm{~g} \mathrm{~L}^{-1}$ )

\begin{tabular}{llll}
\hline Adsorbent & \multicolumn{3}{l}{ Sorption capacity $\left(\mathrm{mg} \mathrm{g}^{-1}\right)$} \\
\cline { 2 - 4 } & $\mathrm{Cu}^{2+}$ & $\mathrm{Pb}^{2+}$ & $\mathrm{Zn}^{2+}$ \\
\hline Pristine biochar & 24.183 & 63.36 & 16.38 \\
MTCB nanocomposite & 25.42 & 76.68 & 24.96 \\
\hline
\end{tabular}

Immobilization of $\mathrm{Cu}^{2+}, \mathrm{Pb}^{2+}$, and $\mathrm{Zn}^{2+}$ in Soil

A synthetic precipitation leaching procedure was performed for a multi-metal system in a soil amended with $10 \% \mathrm{w} / \mathrm{w}$ MTCB. The results of SPLP test reveal that the proposed novel nanobiocomposite is efficient in immobilizing the metals within the soil environment as it reduces the metal leaching from the soil by 100,100 , and $52.29 \%$ for $\mathrm{Cu}^{2+}, \mathrm{Zn}^{2+}$, and $\mathrm{Pb}^{2+}$, respectively. This supports the confidence, that this novel material is applicable for use as an efficient soil amendment for mine impacted soils.

Table 8 draws a comparison between the novel MTCB nanobiocomposite and other previously proposed sorbents for $\mathrm{Cu}^{2+}, \mathrm{Zn}^{2+}$, and $\mathrm{Pb}^{2+}$ immobilization showing the higher loading capacity of MTCB.

\section{Conclusions}

In the present study, a novel nanobiocomposite (MTCB) was synthesized and its sorptive behavior towards three specific heavy metals was evaluated both in single and multi-component systems. The main findings are as follows:

- The composite material possesses a mixed organicinorganic nature: the base biochar has high surface area and its mesoporous structure gives it a unique characteristic as a porous matrix; while the polymer-clay coating imports some active functional groups that are able to efficiently immobilize the heavy metals.

- FT-IR analysis indicates some shifting for active site vibrations of chitosan and montmorillonite nanoclay as a result of exfoliation phenomenon and the interaction of the negatively charged clay surfaces with the active groups of chitosan.

- Single-element experiments show that the sorption isotherm conforms to the Freundlich model in case of $\mathrm{Cu}^{2+}$ and $\mathrm{Zn}^{2+}$; while for $\mathrm{Pb}^{2+}$ it is best represented by Temkin model. The mechanism involved in immobilization of heavy metals is determined as binding with active $\mathrm{NH}_{2}$ groups.

- Moreover, the application of MTCB as a soil amendment was assessed by conducting SPLP tests and the results showed that it can reduce the amount of metal in the leachate through immobilization when added by $10 \% \mathrm{w} / \mathrm{w}$ to the soil. 

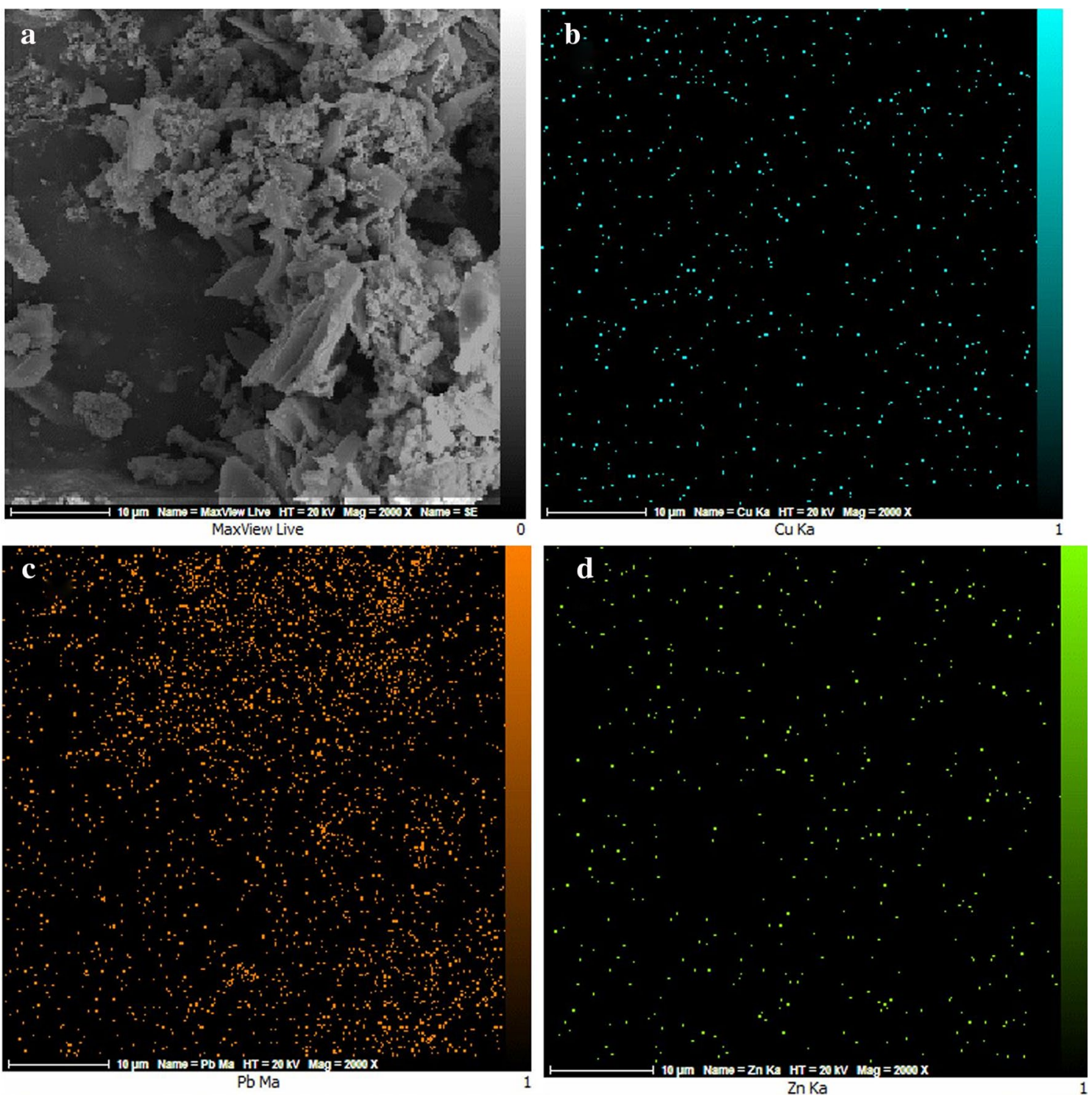

Fig. 10 FE-SEM micrograph showing a surface morphology and EDS elemental mapping analysis for b $\mathrm{Cu}^{2+}, \mathbf{c} \mathrm{Pb}^{2+}$, and $\mathbf{d} \mathrm{Zn}^{2+}$ distribution over the MTCB specimen

Table 8 Comparison of metal sorption capacity between MTCB and some other sorbents

\begin{tabular}{lllll}
\hline Adsorbent & \multicolumn{3}{l}{ Sorption capacity $\left(\mathrm{mg} \mathrm{g}^{-1}\right)$} & Ref. \\
\cline { 2 - 4 } & $\mathrm{Cu}^{2+}$ & $\mathrm{Pb}^{2+}$ & $\mathrm{Zn}^{2+}$ & \\
\hline MTCB nanocomposite & 121.5 & 336 & 134.6 & Current study \\
Corn straw biochar & 12.52 & - & 11.0 & {$[34]$} \\
Hardwood biochar & 6.59 & - & 4.54 & \\
$\begin{array}{l}\text { Chitosan-immobilized } \\
\quad\end{array} \quad 12.6$ & 15 & - & {$[39]$} \\
$\quad$ on bentonite & 59 & 55.5 & - & {$[40]$} \\
\hline
\end{tabular}

Acknowledgements The authors would like to express their sincere thanks to Mazandaran Wood and Paper Industries for their kind cooperation in supply of feedstock materials during this project and also technical helps of Iran Mineral Processing Research Center (IMPRC). The research was financially supported by Iran National Science Foundation (INSF) and Iran Nanotechnology Initiative Council (INIC).

Funding This study was funded by Iran National Science Foundation (INSF) and Iran Nanotechnology Initiative Council (INIC).

\section{Compliance with Ethical Standards}

Conflict of interest Hoda Arabyarmohammadi has received research grants from INIC. Ahmad Khodadadi Darban has received research grant from INSF. 
Open Access This article is distributed under the terms of the Creative Commons Attribution 4.0 International License (http://creativecommons.org/licenses/by/4.0/), which permits unrestricted use, distribution, and reproduction in any medium, provided you give appropriate credit to the original author(s) and the source, provide a link to the Creative Commons license, and indicate if changes were made.

\section{References}

1. Yang J, Pan X, Zhao C et al (2016) Geomicrobiol J 33:261-266

2. Georgiev P, Groudev S, Spasova I, Nicolova M (2015) J Soils Sedim 16:1288-1299

3. Xu R, Zhao A (2013) Environ Sci Pollut Res Int 20:8491-8501

4. Jeyasingh J, Philip L (2005) J Hazard Mater 118:113-120

5. Lehmann J, Gaunt J, Rondon M (2006) Mitig Adapt Strateg Glob Chang 11:395-419

6. Lu H, Zhang W, Yang $\mathrm{Y}$ et al (2012) Water Res 46:854-862

7. Wang H, Gao B, Wang S et al (2015) Bioresour Technol 197:356-362

8. Wang SF, Shen L, Tong YJ et al (2005) Polym Degrad Stab 90:123-131

9. Daraei P, Madaeni SS, Salehi E et al (2013) J Memb Sci 436:97-108

10. Krajewska B (2001) React Funct Polym 47:37-47

11. Yu-shan XIE, Shao-zao TAN, Ma-hua L, Ren-fu LIU (2010) Chem Res Chin Univ 26:509-513

12. Vanamudan A, Pamidimukkala P (2015) Int J Biol Macromol 74:127-135

13. Auta M, Hameed BH (2014) Chem Eng J 237:352-361

14. Monvisade P, Siriphannon P (2009) Appl Clay Sci 42:427-431

15. Kittinaovarat S, Kansomwan P, Jiratumnukul N (2010) Appl Clay Sci 48:87-91

16. Hussein OT (2015) Int J Sci Eng Appl 4:174-185

17. Pandey S, Mishra SB (2011) J Colloid Interface Sci 361:509-520

18. Sabaa MW, Abdallah HM, Mohamed N a., Mohamed RR (2015) Mater Sci Eng C 56:363-373
19. Bleiman N, Mishael YG (2010) J Hazard Mater 183:590-595

20. Kuo S (1996) Phosphorus. In: Sparks DL, Page AL, Helmke PA eds. Methods soil anal. Part 3-chemical methods, RHL, Madison, pp 869-919

21. Balistrieri LS, Murray JW (1981) Am J Sci 281:788-806

22. Srivastava VC, Mall ID, Mishra IM (2008) Chem Eng Process Process Intensif 47:1269-1280

23. Arabyarmohammadi H, Salarirad MM, Behnamfard A (2014) Environ Prog Sustain Energy 33:777-789

24. Temkin MJ, Pyzhev TV (1940) Acta Physiochim USSR $12: 217-222$

25. Sousa Neto VO, Oliveira AG, Teixeira RNP et al (2011) BioResources 6:3376-3395

26. Mayer ZA, Eltom Y, Stennett D et al (2014) Environ Prog Sustain Energy 33:490-496

27. Enders A, Hanley K, Whitman T et al (2012) Bioresour Technol 114:644-653

28. Bansal RC, Goyal M (2005) Activated carbon adsorption, CRC press, Boca Raton

29. Sing KSW (1985) Pure Appl Chem 57:603-619

30. Sirousazar M, Kokabi M, Hassan ZM, Bahramian AR (2011) Sci Iran 18:780-784

31. Xu Y, Ren X, Hanna MA (2006) J Appl Polym Sci 99:1684-1691

32. Choi Y, Shin SYA, Soares JBP (2010) Macromol Chem Phys 211:1026-1034

33. Liu Z, Zhang F-S (2009) J Hazard Mater 167:933-939

34. Chen X, Chen G, Chen L et al (2011) Bioresour Technol 102:8877-8884

35. Plazinski W, Dziuba J, Rudzinski W (2013) Adsorption 19:1055-1064

36. Ho YS, McKay G (1998) Process Saf Environ Prot 76:332-340

37. Singh TS, Pant K (2004) Sep Purif Technol 36:139-147

38. Mall ID, Srivastava VC, Kumar GV a, Mishra IM (2006) Colloids Surf A Physicochem Eng Asp 278:175-187

39. Futalan CM, Tsai W, Lin S, Hsien K (2012) Sustai Environ Res 22(6):345-355

40. Sobhanardakani S, Zandipak R, Parvizimosaed H, Khoei AJ, Moslemi M, Tahergorabi M, Hosseini SM, Delfieh P (2014) Iran J Toxicol 8(26):1145-1151 